Hoàn thiện hệ thống xếp hạng tín dụng nội bộ đối với doanh nghiệp vay vốn tại Ngân hàng Nông nghiệp và Phát triển Nông thôn Việt Nam

\author{
Phan Anh
}

December 24, 2012

Luận văn Thạc sỹ Kinh tế

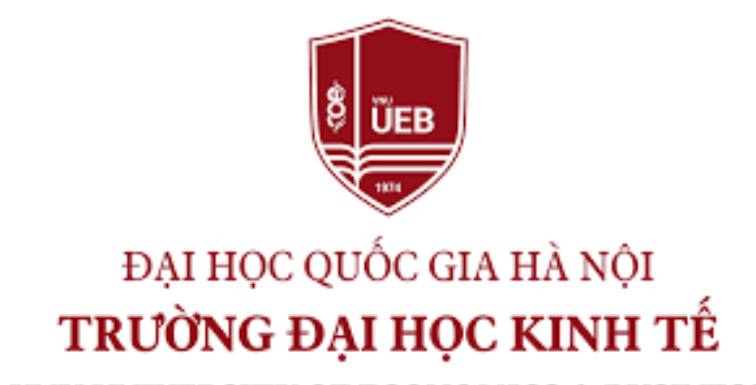

VNU UNIVERSITY OF ECONOMICS \& BUSINESS

Trường Đại học Kinh tế - Đại học Quốc gia Hà Nội 


\title{
Hoàn thiện hệ thống xếp hạng tín dụng nội bộ đối với doanh nghiệp vay vốn tại Ngân hàng Nông nghiệp và Phát triển Nông thôn Việt Nam
}

\section{Phan Anh}

\author{
Trường Đại học Kinh tế \\ Luận văn ThS ngành: Tài chính ngân hàng; Mã số: 603420 \\ Người hướng dẫn: PGS.TS. Nguyễn Kim Anh \\ Năm bảo vệ: 2012
}

\begin{abstract}
Hệ thống hóa những vấn đề lý luận cơ bản Rủi ro tín dụng (RRTD) trong hoạt động ngân hàng và hệ thống xếp hạng tín dụng nội bộ của ngân hàng thương mại (NHTM). Đánh giá thực trạng hoạt động của Ngân hàng Nông nghiệp và Phát triển nông thôn Việt Nam trong thời gian qua, thực trạng hệ thống xếp hạng tín dụng nội bộ của Ngân hàng Nông nghiệp và Phát triển nông thôn Việt Nam để từ đó rút ra những thành tích, tồn tại và nguyên nhân của những tồn tại đó. Đề xuất một hệ thống giải pháp có tính khả thi cho Ngân hàng Nông nghiệp và Phát triển nông thôn Việt Nam để hoàn thiện công tác tham chiếu bộ máy xếp hạng tín dụng (XHTD) nội bộ đồng thời đề xuất bổ sung một số chỉ tiêu đánh giá nhằm giúp hệ thống phát huy tối đa hiệu quả. Áp dụng vào công tác thực tiễn vì Ngân hàng Nông nghiệp và Phát triển nông thôn Việt Nam đang trong quá trình hoàn thiện quy trình tín dụng trong đó có các vấn đề liên quan đến XHTD khách hàng nhằm phù hợp với chính sách tín dụng và cơ cấu tổ chức mới sau cổ phần hóa.
\end{abstract}

Keywords: Tài chính ngân hàng; Tín dụng; Doanh Nghiệp; Vốn; Rủi ro tín dụng

\section{Content}

\section{Tính cấp thiết của đề tài}

Thực tiễn đã cho thấy thất bại của ngân hàng thương mại (NHTM) trong hoạt động tín dụng gắn chặt với thiếu hiểu biết về khách hàng. Một trong những kỹ thuật quản trị rủi ro tín dụng (RRTD) của NHTM là sử dụng phân tích chấm điểm để xếp hạng uy tín về mặt tín dụng của mỗi khách hàng một cách thường xuyên. Do vậy, vấn đề xây dựng và 
hoàn thiện hệ thống xếp hạng tín dụng (XHTD) nội bộ đang được các NHTM quan tâm nhằm ngăn ngừa và hạn chế RRTD, giảm bớt tỷ lệ nợ xấu phải trích dự phòng rủi ro, đáp ứng các yêu cầu của Basel và Ngân hàng Nhà nước (NHNN).

Trong hệ thống NHTM Việt Nam thì Ngân hàng Nông nghiệp và Phát triển nông thôn Việt Nam nằm trong nhóm những ngân hàng lớn cả về vốn chủ sở hữu lẫn số lượng chi nhánh. Hệ thống XHTD nội bộ tại VBARD đã được xây dựng và triển khai ứng dụng từ trước đó, tuy nhiên qua kiểm chứng tình trạng nợ xấu phải trích dự phòng rủi ro của Ngân hàng trong thời gian gần đây vẫn gia tăng. Tình trạng nợ xấu của VBARD gia tăng trong thời gian gần đây đến từ nhiều nguyên nhân cả chủ quan lẫn khách quan có thể kể đến như tình trạng thị trường bất động sản và chứng khoán đóng băng, lạm phát tăng cao, các yêu cầu về quản trị rủi ro NHTM của NHNN ngày một chặt chẽ... nhưng nguyên nhân chủ yếu của tình trạng nợ xấu ngân hàng tăng cao này là nằm ở hệ thống XHTD nội bộ của VBARD chưa hoàn thiện đặc biệt ở công tác XHTD nội bộ đối với doanh nghiệp vay vốn. Theo khảo sát của tác giả nợ xấu của từ phía khách hàng doanh nghiệp của ngân hàng chiếm tỷ trọng rất cao trong tổng số nợ xấu.

Điều này cho thấy hệ thống XHTD nội bộ đối với doanh nghiệp vay vốn của Ngân hàng Nông nghiệp và Phát triển Việt Nam còn nhiều khuyết điểm dẫn đến việc sàng lọc khách hàng chưa đạt được hiệu quả mong muốn.

Xuất phát từ thực trạng đó, tác giả đã mạnh dạn lựa chọn đề tài "Hoàn thiện hệ thống xếp hạng tín dụng nội bộ đối với doanh nghiệp vay vốn tại Ngân hàng Nông nghiệp và Phát triển nông thôn Việt Nam” làm luận văn cao học của mình. Đề tài nghiên cứu của tác giả nhằm đóng góp một số ý kiến vào mục đích hoàn thiện hơn nữa công tác XHTD nội bộ đối với doanh nghiệp vay vốn tại VBARD, tiến tới bổ sung chỉnh sửa hệ thống XHTD nội bộ phù hợp hơn với điều kiện kinh tế xã hội và các hiệp ước quốc tế mà Việt Nam cam kết.

\section{Tình hình nghiên cứu}

Trong quá trình nghiên cứu để thực hiện đề tài, tác giả nhận thấy rằng đề tài nghiên cứu về hoàn thiện XHTD tại các NHTM không phải là một đề tài mới đối với hệ thống tài chính ngân hàng nói chung và một luận văn thạc sỹ nói riêng. Điển hình, dẫn chứng một số nghiên cứu về đề tài này mà tác giả có cơ hội được tham khảo gồm:

- Dinh Thi Huyen Thanh \& Stefanie Kleimeier, 2006, "Credit Scoring for Vietnam's Retail Banking Market” 
- Basel Committee on Banking Supervision, "An explanatory note on the Basel II IRB risk weight functions"

- Nguyễn Trường Sinh, 2009, "Hoàn thiện hệ thống xếp hạng tín nhiệm tại Ngân hàng Thuoong mại Cổ phần Ngoại thuoong Việt Nam"

- Vương Quân Hoàng, Đào Gia Nhân, Nguyễn Văn Hữu, Trần Minh Ngọc, Lê Hồng Phương, 2006 "Phuơng pháp thống kê xây dưng mô hình định mức tín nhiệm khách hàng thể nhân"

- Raymond Anderson, 2007, "The Credit Scoring Toolkit:Theory and Practice for Retail Credit risk Management and Decision Automation"

- Khoa Ngân hàng - Học viện Ngân hàng, Kỷ yếu hội thảo khoa học: "An toàn trong hoạt động kinh doanh của hệ thống NHTM Việt Nam".

- Nguyễn Thị Hoàng Yến - Luận văn Thạc sỹ kinh tế "Giải pháp nâng cao chất luợng xếp hạng tín dụng doanh nghiệp tại trung tâm thông tin tín dụng Ngân hàng nhà nước Việt Nam".

- V.v...

Tuy nhiên, trong tất các các nghiên cứu về đề tài hoàn thiện hệ thống XHTD tại các NHTM chưa có đề tài nào nghiên cứu về hoàn thiện hệ thống XHTD nội bộ đối với doanh nghiệp vay vốn tại VBARD. Đề tài của tác giả tập trung vào đối tượng chính là các doanh nghiệp vay vốn ngân hàng mà chủ thể được nghiên cứu cụ thể trong luận văn là Ngân hàng Nông nghiệp và Phát triển nông thôn Việt Nam. Do đó, tác giả tin rằng đóng góp của đề tài là giúp hoàn thiện tốt hơn hệ thống XHTD nội bộ cho doanh nghiệp vay vốn tại ngân hàng Ngân hàng Nông nghiệp và Phát triển nông thôn Việt Nam nói riêng và cho hệ thống XHTD nội bộ của các NHTM tại Việt Nam nói chung.

\section{Mục đích và nhiệm vụ nghiên cứu}

Đề tài tiếp cận cơ sở lý luận hiện đại về xếp hạng tín nhiệm, phân tích hiện trạng và kiểm chứng các chỉ tiêu đánh giá trong XHTD nội bộ Ngân hàng Nông nghiệp và Phát triển nông thôn Việt Nam so với hệ thống đánh giá xếp hạng tiên tiến của những tên tuổi hàng đầu trong lĩnh vực này như Moody’s và Standard \& Poor's đang được sử dụng hiệu quả tại nhiều nước trên thế giới để dự đoán nguy cơ phá sản và xếp hạng RRTD.

Từ kết quả nghiên cứu này, đề tài sẽ cho thấy được những thành tựu cũng như những hạn chế tồn tại của hệ thống XHTD nội bộ đối với doanh nghiệp vay vốn đang được sử dụng tại Ngân hàng Nông nghiệp và Phát triển nông thôn Việt Nam, qua đó, đề 
tài nghiên cứu mạnh dạn đề xuất những giải pháp góp phần hoàn thiện hệ thống XHTD nội bộ đối với doanh nghiệp vay vốn tại Ngân hàng Nông nghiệp và Phát triển nông thôn Việt Nam bằng cách tiếp thu những tiến bộ trong kinh nghiệm XHTD của các tổ chức tín nhiệm quốc tế, các NHTM và tổ chức kiểm toán trong nước.

\section{4. Đối tượng và phạm vi nghiên cứu của đề tài}

Đối tượng nghiên cứu của luận văn là những vấn đề về lý thuyết và thực tiễn XHTD đối với doanh nghiệp vay vốn tại các tổ chức tín dụng trên Thế giới và tại Việt Nam, cũng như tình hình hoạt động và thực trạng công tác đó tại Ngân hàng Nông nghiệp và Phát triển nông thôn Việt Nam. Đồng thời, luận văn nghiên cứu một số giải pháp nhằm hoàn thiện hơn công tác XHTD nội bộ đối với doanh nghiệp vay vốn tại Ngân hàng Nông nghiệp và Phát triển nông thôn Việt Nam. Số liệu trong khoá luận được tập hợp chủ yếu trong khoảng thời gian từ năm 2001-2011.

Phạm vi nghiên cứu của đề tài là:

a. Các vấn đề về hệ thống XHTD bao gồm tổng quan về XHTD, thực tiễn XHTD tại Việt Nam.

b. Thực trạng hệ thống XHTD nội bộ đối với doanh nghiệp vay vốn tại Ngân hàng Nông nghiệp và Phát triển nông thôn Việt Nam. Từ đó luận văn tiến hành phân tích, đánh giá, so sánh và kiểm chứng các chỉ tiêu đánh giá trong mô hình chấm điểm để rút ra được những thành tựu cũng như các hạn chế tồn tại cần hoàn thiện, bổ sung nhằm tăng cường hiệu quả ngăn ngừa và giảm thiểu RRTD qua hệ thống sàng lọc khách hàng.

c. Các giải pháp thực tiễn góp phần hoàn thiện Hệ thống XHTD nội bộ đối với doanh nghiệp vay vốn tại Ngân hàng Nông nghiệp và Phát triển nông thôn Việt Nam.

\section{Phương pháp nghiên cứu và tiếp cận vấn đề}

Luận văn sử dụng phương pháp nghiên cứu tình huống để tiếp cận chuyên môn về đối tượng nghiên cứu theo nội dung, phương pháp, và kỹ thuật xếp hạng tín nhiệm của Ngân hàng Nông nghiệp và Phát triển nông thôn Việt Nam.

Luận văn sử dụng phương pháp phân tích số liệu định tính và định lượng để làm rõ hiện trạng hệ thống XHTD nội bộ. Đồng thời bằng cách sử dụng phương pháp so sánh với các tiêu chuẩn đánh giá phổ biến trong hệ thống xếp hạng tín nhiệm quốc tế và trong nước, qua đó, nghiên cứu để đưa ra nhận định, đề xuất giải pháp hoàn thiện hệ thống XHTD nội bộ đối với doanh nghiệp vay vốn tại Ngân hàng Nông nghiệp và Phát triển nông thôn Việt Nam. Số liệu trong luận văn được tập hợp chủ yếu trong khoảng thời gian 
từ năm $2007-2011$.

\section{Dự kiến đóng góp mới của luận văn}

Thứ nhất, hệ thống hóa những vấn đề lý luận cơ bản RRTD trong hoạt động ngân hàng và hệ thống xếp hạng tín dụng nội bộ của NHTM.

Thứ hai, đánh giá thực trạng hoạt động của Ngân hàng Nông nghiệp và Phát triển nông thôn Việt Nam trong thời gian qua, thực trạng hệ thống xếp hạng tín dụng nội bộ của Ngân hàng Nông nghiệp và Phát triển nông thôn Việt Nam để từ đó rút ra những thành tích, tồn tại và nguyên nhân của những tồn tại đó.

Thứ ba, đề xuất một hệ thống giải pháp có tính khả thi cho Ngân hàng Nông nghiệp và Phát triển nông thôn Việt Nam để hoàn thiện công tác tham chiếu bộ máy XHTD nội bộ đồng thời đề xuất bổ sung một số chỉ tiêu đánh giá nhằm giúp hệ thống phát huy tối đa hiệu quả.

Thứ tư, kết quả của đề tài nghiên cứu này có thể được áp dụng vào công tác thực tiễn vì Ngân hàng Nông nghiệp và Phát triển nông thôn Việt Nam đang trong quá trình hoàn thiện quy trình tín dụng trong đó có các vấn đề liên quan đến XHTD khách hàng nhằm phù hợp với chính sách tín dụng và cơ cấu tổ chức mới sau cổ phần hóa.

\section{Kết cấu của đề tài}

Ngoài “Lời mở đầu” và "Kết Luận”, luận văn gồm 3 chương:

Chương 1: CƠ SỞ LÝ LUẬN VỀ HOẠT ĐỘNG XẾP HẠNG TÍN DỤNG ĐỐI VỚI DOANH NGHIỆP VAY VỐN TẠI CÁC NGÂN HÀNG THƯƠNG MẠI

Chương 2: THỰC TRANG HOAT ĐÔNG XÊP HANG TÍN DUNG NÔI BÔ ĐỐI VỚI DOANH NGHIÊP VAY VỐN TẠI NGÂN HÀNG NÔNG NGHIÊP VÀ PHÁT TRIỂN NÔNG THÔN VIÊT NAM

Chương 3: GIẢI PHÁP HOÀN THIÊN HÊ THỐNG XẾP HẠNG TÍN DƯNG NÔII BÔ ĐỐI VỚI DOANH NGHIÊP VAY VỐN TAI NGÂN HÀNG NÔNG NGHIÊP VÀ PHÁT TRIỂN NÔNG THÔN VIÊT NAM

\section{References}

\section{TIẾNG VIẸT}

[1]. Báo cáo tổng kết tín dụng Ngân hàng Nông nghiệp và phát triển nông thôn Việt nam năm 2007, năm 2008, năm 2009, năm 2010, năm 2011. 
[2]. Dự án quỹ phát triển doanh nghiệp vừa và nhỏ (2006), Quản lý danh muc cho vay doanh nghiệp vì̀a và nhỏ.

[3]. Học viện ngân hàng, Giáo trình tín dụng, Nhà xuất bản thống kê

[4]. Lê Thanh Tâm (2008), Phát triển các tổ chức tài chính nông thôn Việt Nam, Luận án Tiến sỹ, Trường Đại học Kinh tế quốc dân.

[5]. Lê Thị Xuân (2008), Giáo trình phân tích hoạt động kinh doanh, Học viện ngân hàng.

[6]. Lê Thị Huyền Diệu (2010), Luận cứ khoa học về xác định mô hình quản lý rủi ro tín dụng tại hệ thống ngân hàng thuoong mại Việt Nam, Luận án Tiến sỹ, Học viện Ngân hàng Hà Nội.

[7]. Ngân hàng Nhà nước Việt Nam (2001), Quy chế cho vay của Tổ chức tín dụng đối với khách hàng ban hành tại Quyết định 1627/QĐ-NHNN ngày 31/12/2001.

[8]. Ngân hàng Nhà nước Việt Nam (2005), Quy định về các tỷ lẹ bảo đảm an toàn trong hoạt động của TCTD, tại Quyết định 457/2005/QD-NHNN

[9]. Ngân hàng Nhà nước Việt Nam (2005), Quy định về phân loại nợ, trích lập và sư dụng dụ phòng để xử lý rủi ro tín dụng trong hoạt động ngân hàng ban hành tại Quyết định 493/2005/QĐ-NHNN ngày 22/4/2005

[10]. Ngân hàng Nhà nước Việt Nam (2005), về việc sưa đổi bổ sung quyết định 127/2005/QĐ-NHNN về việc việc ban hành Quy chế cho vay của TCTD đối với khách hàng tại Quyết định 783/2005/QĐ-NHNN ngày 31/5/2005

[11]. Ngân hàng Nhà nước Việt Nam (2005), Về việc về việc sủa đổi, bổ sung một số điều trong Quy chế cho vay của TCTD đối với khách hàng ban hành theo quyết định 1627/ QĐ-NHNN ngày 31/12/2001 của Thống đốc NHNN tại Quyết định 127/2005/QĐ-NHNN ngày 3/2/2005.

[12]. Ngân hàng Nhà nước Việt Nam (2007), quy định về sửa đổi bổ sung quyết định 493/2005/QĐ-NHNN ban hành tại Quyết định 18/2007/QĐ-NHNN ngày $25 / 4 / 2007$

[13]. Ngân hàng Nhà nước Việt Nam (2007), về việc sưa đổi bổ sung một số điều của quyết định 457/2005/QD-NHNN ban hành tại Quyết định 03/2007/QĐ-NHNN

[14]. Ngân hàng Nông nghiệp và phát triển nông thôn Việt Nam (2008), Hệ thống hóa các văn bản định chế của Ngân hàng nông nghiệp và phát triển nông thôn Việt Nam. 
[15] Vương Quân Hoàng, et al. (2006). Phương pháp thống kê xây dựng mô hình định mức tín nhiệm khách hàng thể nhân. Vietnam Journal of Mathematical Applications, 4(2), 1-16.

[16] Raymond Anderson. (2007). The Credit Scoring Toolkit:Theory and Practice for Retail Credit Risk Management and Decision Automation. Oxford: Oxford University Press.

[17] Dinh Thi Huyen Thanh \& Stefanie Kleimeier. Credit Scoring for Vietnam's Retail Banking Market: Implementation and Implications for Transactional Versus Relationship Lending. METEOR, Maastricht research school of Economics of TEchnology and ORganizations, 2006. 